\title{
Impact of Consumer Behavior Pertaining to Personalization of Price in an E-Commerce Context
}

\author{
Jensolin Abitha Kumari J ${ }^{*}$, Preeti R. GOTMARE ${ }^{* *}$
}

Received: November 4, 2021. Revised: December 17, 2021. Accepted: December 18, 2021.

\begin{abstract}
The study focuses on developing a conceptual model to explore the factors influencing consumers' judgments in the decision-making process with a prime focus on personalized dynamic pricing (PDP). The study explored the judgmental impact of $P D P$ on customer willingness to pay and mediating role of stickiness to the online store on PDP fairness and customer willingness to pay. The data was collected using a structured questionnaire administered among 256 students at a large university in India. SEM using AMOS software was used to analyze data. Price perception, involvement, product knowledge, and recommendation system positively impact price fairness of PDP, directly and indirectly influencing customer willingness to pay. Results also showed that stickiness to online stores fully mediates the relationship between price fairness of PDP and customer willingness to pay. Theoretically, the study contributes to pricing and marketing literature by identifying the antecedents of price fairness of PDP. For practitioners, this study signifies the importance of a robust recommendation system to stand out from the competition and provide deals to satisfy consumers. Specifically, the results emphasize the need to focus on stickiness to an online store to track consumer characteristics and customer value.
\end{abstract}

Keywords: Personalized dynamic pricing, stickiness to an online store, customer willingness to pay, recommendation system, price fairness.

JEL Classification Codes : M31, M39

UDC : 338.51

DOI : https://doi.org/10.17015/ejbe.2021.028.06.

\footnotetext{
* Ph.D. Scholar, Department of Management, Central University of Tamil Nadu, India. E-mail: jensolin18@students.cutn.ac.in

${ }^{* *}$ Assistant Professor, Department of Management, Central University of Tamil Nadu, India. E-mail: preetigotmare@cutn.ac.in
}

Copyright (C), 2021 Ala-Too International University. 


\section{Introduction}

Personalization of prices is gaining popularity as a viable pricing option in an online context (Priester et al., 2020). Personalized pricing improves a firm's profit by $19 \%$ compared to optimized uniform pricing and $86 \%$ compared with the firm's status quo pricing. Moreover, personalized pricing can benefit more than $60 \%$ of customers compared to the firm's uniform pricing (Dubé \& Misra, 2019). Technological advancements and data analytics enable online retailers to adopt dynamic pricing strategies that help identify and track individual online consumers on a real-time basis (Priester et al., 2020).

Personalized dynamic pricing (PDP) is influenced by consumers' prior experience, interpersonal price comparison, date, time of purchase, gender, location, device used (Lastner et al., 2019), buyers' cultural differences, social norms in setting the price (Garbarino \& Maxwell, 2010; Broeder \& Wildeman, 2020) and the quantity purchased. Existing literature has studied the impact of PDP on consumer trust, loyalty, seller choice, price-setting mechanism, and competitor prices. Also, another stream of research focuses on regulatory implications of PDP, such as privacy concerns, legal concerns, societal and consumer welfare implications (Priester et al., 2020).

Customer perception of PDP can impact a firm's positioning and pricing strategies among its competitors (Krämer \& Kalka, 2017). Hence this paper explores the role of price perception of PDP and its impact on customer willingness to pay in an Indian ecommerce context. Moreover, recent reports highlight the need for a comprehensive study on the advantages of PDP for consumers (Acquisti et al., 2016; Priester et al., 2020) and understanding PDP from the customer's perspective (Dubé $\&$ Misra, 2019). Our paper explores these research gaps. Objectives of this study are:

- To explore the role of price consciousness, involvement, product knowledge, and recommendation system in influencing price perception of PDP and customer willingness to pay

- To examine whether stickiness to online stores mediates the relationship between price perception of PDP and customer willingness to pay.

\section{Literature Review}

\subsection{PDP and Price Fairness Perception}

The first step of online shopping would be the entry of a search query by the consumer. The e-commerce platform displays a two-stage search result, for which the recommendation system considers the data comprising detailed browsing histories by each consumer. Ideally, a list of relevant products which a consumer can choose from appears. Second, consumers evaluate only a handful of products based on price, features, and reviews, which form the consideration set. Browsing data 
from these two product/price search stages can be used by e-commerce firms to estimate consumer demand and provide personalization of the marketing mix (Dinerstein et al., 2018).

Following is an overview of how e-commerce firms use online consumer data to provide personalized dynamic pricing. Internet-based technology-mediated platforms enable e-commerce firms to track all individual customer activities. Online consumers are the source for data in analytics and recommendation system (Dinerstein et al., 2018). Firms need to comprehend how consumers select, use, and dispose of products and services to understand consumer behavior. The paper conceptualizes the consumer buying process in 3 stages: pre-purchase, purchase, and post-purchase (Lemon \& Verhoef, 2016). We emphasize the series of activities in the pre-purchase phase, where a consumer pays attention to price during a product search in a platform. While shopping online, consumers use multiple modes to search prices of products (Dinerstein et al., 2018). E.g., a consumer looking to purchase a product online may check for the price listed in e-commerce platforms like Amazon, Flipkart, etc., or use comparison sites or price tracking tools like Keepa to track price fluctuations. Next, a consumer may sign in or not, view incognito mode, or ask friends/family to check for the price. Based on these activities, consumers form price perception.

Price perception is the evaluation of a specific price by consumers. "Fair" is a global measure of price acceptability (Lichtenstein et al., 1988). One stream of literature on price fairness literature explores factors influencing fairness perception and other consequences of fairness perception. Prior research has examined fairness perception of PDP in diverse contexts and its relationship with other constructs like customer's evaluation of price (reference price) and retailer price. The study adopts the definition by Xia et al. (2004) that defines price fairness as "customers' perceptions and their related emotions about how fair, acceptable, and reasonable the difference is between two prices."

The study draws from equity theory to explain how consumers perceive the price. It states that fairness depends on how much consumers are aware of and compare themselves with others' situations (Adams, 1965). Consumers would compare input or output with others to bring to or receive from the same setting. The theory explains price fairness in terms of equality, advantaged inequality (actual price is lower when compared to reference price), and disadvantaged inequality (actual cost is higher when compared to reference price). In advantaged inequality outcome, the actual price is lower than the reference price. Moreover, purchase history-based personalized dynamic price is fairer as consumers link the offered display price to their behavior based on purchase history (Priester et al., 2020). Hence, consumers justify the price received from the e-commerce store and consider it fair due to advantaged inequality. 


\section{Conceptual Model}

Drawing from equity theory, the conceptual model is developed to include antecedents that influence the perception of PDP and its impact on willingness to pay mediated by stickiness to an online store. Existing literature provides evidence that price consciousness (Zielke \& Komor, 2015), product knowledge (Chen et al., 2019), involvement (Koufaris et al., 2001), and recommendation system (Hazee et al., 2017) influence PDP judgments of consumers in the decision-making process. Hence, the study uses these variables in the conceptual model.

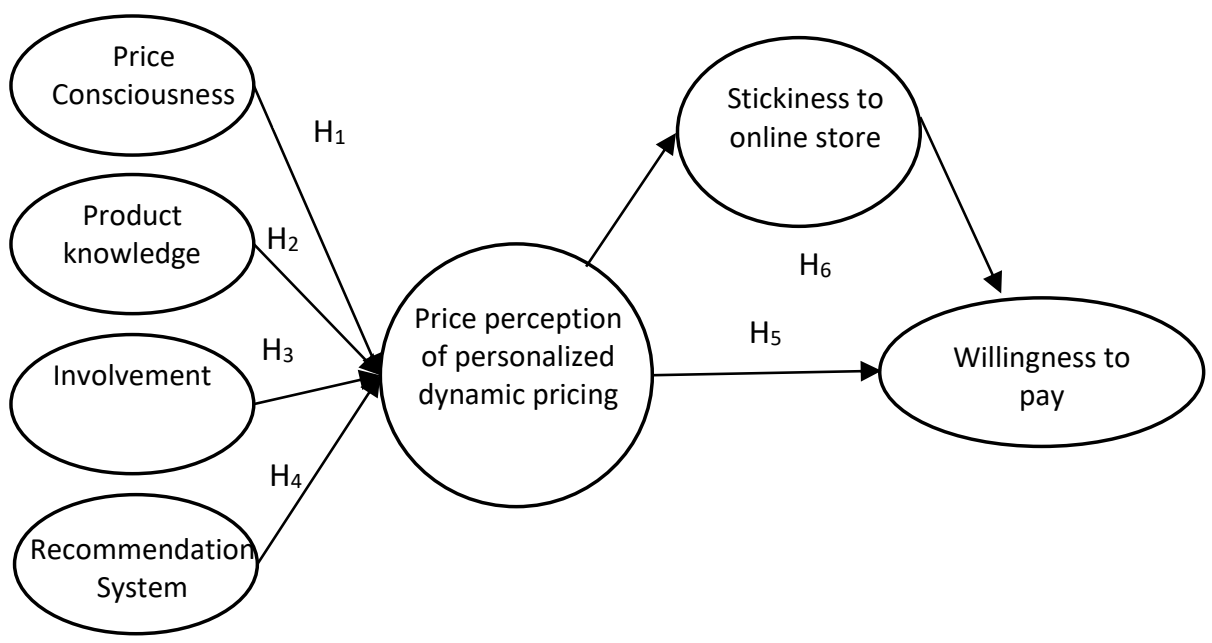

Figure 1: Proposed model and hypotheses

\subsection{Price Consciousness}

Consumers prefer online shopping due to convenience and relatively lower prices than an offline store. The intention to find out the lower price is defined as price consciousness, and it impacts consumer price perception (Zielke \& Komor, 2015). Through their cognitive process, consumers perceive the price of a product and convert them into meaningful information. Price consciousness helps consumers evaluate price cues (Lichtenstein et al., 1988). In the PDP context, consumers view, track, encode the price displayed in an online store and assign meaning to the price to make it more personal or psychological. One of the antecedents for psychologically consumers accepting the product's price is price consciousness. Technology has enabled consumers to search for lower prices and better deals. Hence, we posit:

H1: Price consciousness will play a positive role in influencing price perception of PDP 


\subsection{Product Knowledge}

Product knowledge is defined as the familiarity and expertise of a product (Rao \& Sieben, 1992). Familiarity depends on the purchase, use, or experience of a product. The ability to perform product-related tasks is expertise. Highly knowledgeable consumers fully process product information, including price. They perceive the product to have high quality will be willing to pay more. Consumers acquire product knowledge through product descriptions and visual aids. Consumer product knowledge influences their purchase decisions (Chen et al., 2019). Based on this, we posit:

$\mathrm{H}$ 2: Product knowledge will play a positive role in influencing price perception of PDP

\subsection{Product Involvement}

Consumer involvement in a product impacts its price acceptability. The degree to which the product is essential to the buyer is product involvement (Zaichkowsky, 1985). Product involvement positively influences information search behavior. When product involvement is high, consumers dedicate a significant amount of time and effort to decide on their choice. In an online context, involvement impacts consumers' decision to return to the store (Koufaris et al., 2001). Highly involved online consumers read through the product description, browse the image gallery, and watch demo videos (Sheth \& Unnikrishnan, 2020). The impact of involvement on price perception varies depending on the type of product purchased, either durable or convenience goods. Hence, we posit,

H3: Product involvement will play a positive role in influencing price perception of personalized dynamic price.

\subsection{Recommendation System}

A recommendation system is defined as a system that generates a personalized, optimized experience for a customer selected from discrete options (Burke et al., 2011). A personalized pricing recommendation system provides price personalization using customer data such as preferential data and purchasing histories. Algorithms predict customers' preference patterns based on preferential data. Consumer preference patterns and purchase histories determine price discounts. The precision and prediction accuracy of the recommendation system impact consumers' reliability on the recommendation system and influence consumer purchase decisions (Burke et al., 2011). Consumers using an e-commerce platform should consider the reliability of other consumer behavior because the behavior of other users also impacts personalization (Hazee et al., 2017). Consumers can get reliable recommendations and price personalization which influence consumer willingness to pay (Lee \& Rha, 2016). Hence, we posit:

H4: Recommendation system will play a positive role in influencing price perception of personalized dynamic price. 


\subsection{Impact of PDP on Willingness to Pay}

In today's digital world, consumers interact with firms through a myriad of touchpoints comprising multiple media and channels (Lemon \& Verhoef, 2016). Hence, switching between stores and price information is readily available at minimal search cost. Considering the dynamic nature of PDP, the product's price could vary multiple times within a day. When price difference exists, price perception is affected, influencing willingness to pay (Basaran \& Buyukyilmaz, 2015; Sheikh \& Basti, 2015). The study identifies consumers' willingness to pay as an outcome of consumers' perception of personalized dynamic pricing. Thus, we posit:

H5: Price perception of PDP will play a positive role in influencing customers' willingness to pay.

\subsection{Stickiness to Online Store (SOS) on Customer's Willingness to Pay}

Digitally influenced consumers in India search for at least 2-3 weeks before making their purchase decision (Sheth \& Unnikrishnan, 2020). This behavior can influence the personalization of services by online retailers, where consumers may be aware or unaware of what they do during the pre-purchase phase (Jain et al., 2019). Before making a purchase, potential shoppers browse more than 20 product pages for a few categories and 50 to 60 product pages for specific product categories like mobile phones and women's ethnic wear, and they spend less than 9 minutes per visit on an e-commerce platform in India (Sheth \& Unnikrishnan, 2020). Stickiness is a critical success factor. It helps e-commerce platforms to measure the duration of each visit, helps retain online customers and prolong their period during each stay. Personalization in online services results in a higher level of enjoyment that further leads to increased intention to stay longer and to use or purchase from the online store, thereby leading to customer willingness to pay. SOS is used to measure the frequency and duration of the visit by a consumer. Next, to find out the impact of stickiness on an online store, we study its role as a mediator on WTP and price perception of PDP (Roy et al., 2014). Hence, we posit:

H6: In a PDP context, stickiness to an online store will mediate the effect of price perception of PDP and customer willingness to pay.

\section{Research Methodology}

\subsection{Sample and Data Collection}

The study used data collected from students at a large university in India for hypothesis testing. Students are the most innovative and active users of websites, apps, and online shoppers (Gefen et al., 2003). Wang et al. (2001) state that using students as the sample for online studies is justified because they are the same as online customers for their psychological processes. Moreover, students have access to the internet and use them for communication and transaction purposes hence justified for using them as in sample online research and e-retailing studies. To check 
whether the personalized dynamic pricing phenomenon exists during the study period, we conducted a price tracking exercise using multiple accounts with different browsing characteristics (Richard et al., 2016). Within half an hour, we noticed different prices for consumers, as shown in Table 1 below. The study used the information in Table 1 to describe the scenarios while asking participants to respond to our survey.

\section{Table 1: Price tracking of personalized dynamic pricing from a leading e- commerce website in India}

\begin{tabular}{ccclcc}
\hline $\begin{array}{c}\text { S } \\
\text { No }\end{array}$ & Date & Timestamp & Customer account type & $\begin{array}{c}\text { Price } \\
\text { displayed }\end{array}$ & $\begin{array}{c}\text { Offers } \\
\text { suggested }\end{array}$ \\
\hline 1 & 17.1 .2019 & $11.32 \mathrm{am}$ & Without Signing In & Rs.37,999 & 2 offers \\
\hline 2 & 17.1 .2019 & $11.34 \mathrm{am}$ & New user & Rs.37,999 & 2 offers \\
\hline 3 & 17.1 .2019 & $11.33 \mathrm{am}$ & $\begin{array}{l}\text { Intermittent shopper with low } \\
\text { purchase value }\end{array}$ & Rs.37,999 & 3 offers \\
\hline 4 & 17.1 .2019 & $11.36 \mathrm{am}$ & $\begin{array}{l}\text { Regular customer with high } \\
\text { purchase value }\end{array}$ & Rs.39,200 & 1 offer \\
\hline 5 & 17.1 .2019 & $11.38 \mathrm{am}$ & $\begin{array}{l}\text { Non-regular customer with high } \\
\text { purchase value and purchased } \\
\text { the same model }\end{array}$ & Rs.39,200 & 1 offer \\
\hline
\end{tabular}

The respondents were asked to go through the given scenario and respond to the questionnaire. The scenario adapted and modified from Richard et al. (2016) read as follows, "Imagine you planned to purchase an Air conditioner and to search for a model. Your friend purchased a model a few days back for Rs. 38,500. Interested in buying the same model, you check for the price and ask your family members to see the price displayed. You see the price as shown in Table 1. How would you perceive the price displayed? Based on your perception, kindly fill the questionnaire". The students responded to the survey based on their online shopping experience on a five-point Likert scale. Data were collected through online Google forms questionnaire and pen and paper from April 2019 to September 2019 from 500 respondents, out of which 280 completed the survey. Twenty-four responses were removed because of incomplete responses. Finally, 256 valid responses were accepted with a response rate of $51 \%$. The demographic profile of the sample size (256) comprised $59.7 \%$ male and $40.3 \%$ female respondents and belonged to the age group of $18-32$ years.

\subsection{Research Instrument}

Measure for price consciousness adopted from Lichtenstein et al. (1993) consists of 3 items modified for our study. Product knowledge has three items adapted from Brucks (1985). Involvement consists of 5 items (Zaichkowsky, 1985). Recommender system (5 items) measures from Lee and Rha (2016) and price perception measure 
consist of 3 items adopted from Xia et al., 2004. Measures for willingness to pay consisted of 3 items (Richards et al., 2016), and stickiness to online store consisted of 3 items from Lin (2007). All items were pilot tested on a sample of 31 and had a high-reliability score with Cronbach's alpha coefficients above the recommended level of 0.7. Table 2 shows the measurement instrument.

\subsection{Data Analysis and Results}

Data assessed for normality assumption using Maximum Likelihood (ML) estimation revealed that kurtosis and skewness of variables in the study were between -1.117 to 1.393 and -1.012 to 0.933 respectively and well within the recommended acceptable range of \pm 1.96 for ML estimation (Bollen \& Stine, 1992).

\subsubsection{Measurement Model}

A two-stage structural equation modeling used AMOS 22.0 to test the measurement model and analyze the structural model (Anderson \& Gerbing, 1988). Confirmatory factor analysis (CFA) confirmed construct validity of the constructs using the bootstrapping method with $n=2,000$ at $90 \%$ confidence level, and bias-corrected intervals were executed. Table 2 summarizes CFA results. We modeled factors using the $M L$ approach. The model had excellent reliability with fit indices $\chi 2=337.1$, d.f. $=$ $197, \mathrm{p}$-value $=.000, \mathrm{RMSEA}=0.41, \mathrm{SRMR}=0.053, \mathrm{CFI}=0.972$ which is well within the recommended cut off limit (RMSEA $<0.06$, SRMR $<0.08$, CFI $>0.95$ ). Thus, the model shows a good fit (Hu \& Bentler, 1999). Other fit indices (NFI = 0.93, AGFI = $0.94)$ were also high, showing a good fit.

\section{Table 2: Measurement model results}

\begin{tabular}{|c|c|c|c|c|c|c|}
\hline Scale items & $\begin{array}{l}\text { Factor } \\
\text { loadings } \\
(\lambda)\end{array}$ & $\begin{array}{l}\text { Cronbach } \\
\text { alpha }(\alpha)\end{array}$ & $\begin{array}{l}\text { Composite } \\
\text { Reliability }\end{array}$ & AVE & Mean & SD \\
\hline \multicolumn{7}{|l|}{ Price consciousness } \\
\hline $\begin{array}{l}\text { I am more willing to take extra effort to find } \\
\text { lower prices }\end{array}$ & 0.76 & & & & 3.75 & 0.77 \\
\hline $\begin{array}{l}\text { I believe the time it takes to find low prices } \\
\text { is worth the effort. }\end{array}$ & 0.82 & 0.85 & 0.86 & 0.65 & 3.94 & 0.84 \\
\hline $\begin{array}{l}\text { I believe that money saved by finding lower } \\
\text { prices is worth the time. }\end{array}$ & 0.79 & & & & 3.79 & 0.93 \\
\hline \multicolumn{7}{|l|}{ Product knowledge } \\
\hline The product information given on a retailer & 0.89 & & & & 2.33 & 0.91 \\
\hline website is clear enough to me. & 0.98 & 0.92 & 0.75 & 0.53 & 2.39 & 0.90 \\
\hline \multicolumn{7}{|l|}{ It is clear to me how the product works. } \\
\hline I know exactly what the product is. & 0.85 & & & & 2.41 & 0.89 \\
\hline \multicolumn{7}{|l|}{ Involvement } \\
\hline $\begin{array}{l}\text { I would be interested in reading information } \\
\text { about how the product is made. }\end{array}$ & 0.68 & & & & 3.83 & 0.94 \\
\hline
\end{tabular}


Impact of Consumer Behavior Pertaining to Personalization of Price in an E-Commerce Context

I would be interested in reading the consumer reviews and checking price comparison sites about this product

I compare product characteristics among

brands.

brands.

product.

\section{Recommender System}

Through recommender system,

I can get personalized prices tailored to my

interests and needs.

I can get personalized prices tailored to my

0.76

0.90

0.88

$0.57 \quad 3.46$

activity contexts.

shopping patterns.

I can reduce my time and effort in finding

and conveniently.

Price perception of PDP

Personalized dynamic pricing is fair.

0.76

0.82

3.72

0.83

Personalized dynamic pricing is acceptable.

0.66

0.85

0.62

3.75

0.74

Personalized dynamic pricing is reasonable.

0.63

3.86

0.92

Willingness to pay

I am willing to pay the price displayed on a

retail website

I am willing to pay the price displayed based

0.89

0.85

3.66

0.85

on my preferences

0.83

3.77

0.83

on my purchase and browsing history

Stickiness to an online store

I intend to continue using an online store for

0.94

3.33

0.92

shopping.

I intend to purchase from an online store in

$3.32 \quad 0.95$

the future.

I spend more time on a retail website than

0.73

0.91

0.88

0.69

$3.47 \quad 1.04$

other comparable websites

0.67

$3.50 \quad 0.95$

other comparable websites

I spend more money on a retail website

0.58

than on other comparable websites

Note: ${ }^{* * *}$ Statistically significant at $\mathrm{p}<0.001$

The convergent validity was measured by examining the parameter estimates. The item to total correlation values range from 0.75 to 0.88 , and the average variance 
extracted (AVE) ranges from 0.53 to 0.65 , thereby showing high convergent validity (Fornell \& Larcker, 1981). Also, the average variance extracted of the factors exceeded the squares of its correlation with other constructs, showing discriminant validity of the measures (Fornell \& Larcker, 1981).

Table 3: Discriminant validity

\begin{tabular}{lccccccc}
\hline & RS & PC & PK & I & PP & SOS & WTP \\
\hline Recommender system (RS) & $\mathbf{0 . 7 5}$ & & & & & & \\
\hline Price consciousness (PC) & 0.01 & $\mathbf{0 . 8 1}$ & & & & \\
\hline Product knowledge (PK) & 0.17 & -0.03 & $\mathbf{0 . 7 3}$ & & & \\
\hline Involvement (I) & 0.01 & 0.59 & -0.13 & $\mathbf{0 . 7 7}$ & & & \\
\hline Price perception of PDP (PP) & 0.12 & .03 & 0.42 & 0.09 & $\mathbf{0 . 8 3}$ & & \\
\hline $\begin{array}{l}\text { Stickiness to online store } \\
\text { (SOS) }\end{array}$ & 0.18 & 0.43 & 0.34 & -0.56 & 0.20 & $\mathbf{0 . 7 9}$ & \\
\hline Willingness to pay (WTP) & 0.35 & 0.23 & 0.02 & 0.35 & 0.25 & 0.54 & $\mathbf{0 . 7 5}$ \\
\hline
\end{tabular}

\subsubsection{Common Method Bias}

The study took several precautions to minimize common method variance (CMV) impact. First, the study did not collect personal information to ensure the anonymity of responses. Second, a five-point Likert scale format to reduce the commonalities in scale endpoints and anchoring effects. Harman's single-factor test was used to examine potential common method bias (Podsakoff et al., 2012). In a one-factor solution, our data had $24.65 \%$ of an eigenvalue which is lesser than the recommended critical value of $50 \%$. This result confirms that our model is free from common method bias and CMV is not a significant problem in this study (Podsakoff et al., 2012).

\subsubsection{SEM Results}

Using AMOS 22, the structural model represented in Figure 1 was tested. Table 4 shows the results. Structural model had good fit indices with $\chi 2=386.512, \mathrm{df}=161$, $\chi 2 / \mathrm{df}=2.400, \mathrm{RMSEA}=.055(\mathrm{RMSEA}<0.06), \mathrm{SRMR}=0.068(\mathrm{SRMR}<0.08)$ and CFI $=$ 0.968 ( $C F I>0.95$ ) with all indices higher than the recommended cut off values. Other fit indices NFI $=0.93, \mathrm{AGFI}=0.94$ also showed a good fit. The results were analyzed and found to support all our hypotheses. Results indicated that price perception has a significant positive impact on price perception of PDP $(\beta=0.12, p<0.01)$, thereby supporting $\mathrm{H} 1$. Product knowledge has a significant positive impact on price perception of PDP $(\beta=0.11, p<0.05)$, supporting $\mathrm{H} 2$. 


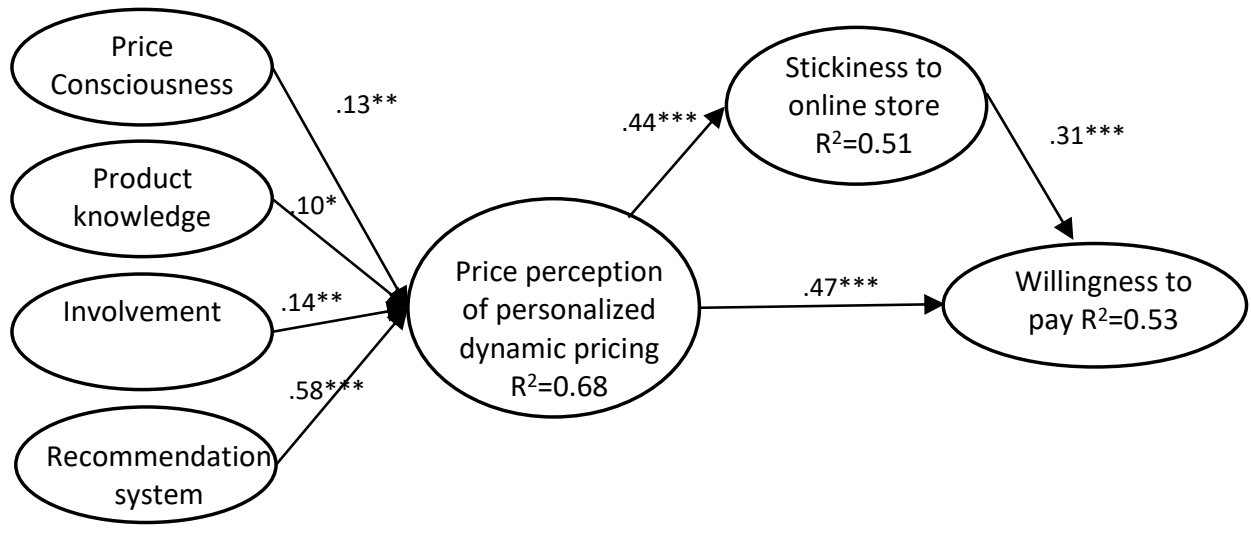

\section{Figure 2: Structural Model with Beta Coefficients of Direct and Indirect Effects \\ Note: ${ }^{*} \mathrm{p}<0.05 ; * * \mathrm{p}<0.01 ; * * * \mathrm{p}<0.001$}

Involvement has a significant positive impact on price perception of PDP $(\beta=0.16$, $p<0.01)$, supporting $H 3$. The recommender system significantly affects price perception on PDP $(\beta=0.48, p<0.001)$, thereby supporting $H 4$. The results showed a significant positive impact of price perception of PDP on WTP $(\beta=0.47 p<0.001)$, thereby supporting H5. SOS causally affects WTP. We calculated the mediating parameters in a model simultaneously. We adopted a user-defined estimand in AMOS to test the hypothesized indirect effect (Gaskin, 2016). As predicted, SOS plays a mediating role in impacting willingness to pay $(\beta=0.28, p<0.001)$, supporting $H 6$. The results show that stickiness mediates the relationship between price perception of PDP and willingness to pay.

\section{Table 4. Hypotheses and results}

\begin{tabular}{llll}
\hline Hypotheses & $\begin{array}{l}\text { Path } \\
\text { coefficient }\end{array}$ & $\begin{array}{l}\text { t- } \\
\text { value }\end{array}$ & Result \\
\hline $\mathrm{H}_{1}:$ Price Consciousness $\rightarrow$ Price perception of PDP & $0.12^{* *}$ & 2.69 & Supported \\
\hline $\mathrm{H}_{2}:$ Product Knowledge $\rightarrow$ Price perception of PDP & $0.11^{*}$ & 2.01 & Supported \\
\hline $\mathrm{H}_{3}:$ Involvement $\rightarrow$ Price perception of PDP & $0.16^{* *}$ & 2.85 & Supported \\
\hline $\mathrm{H}_{4}:$ Recommender System $\rightarrow$ Price perception of PDP & $0.58^{* * *}$ & 8.96 & Supported \\
\hline $\mathrm{H}_{5}:$ Price perception of PDP $\rightarrow$ WTP & $0.47^{* * *}$ & 7.76 & Supported \\
\hline $\mathrm{H}_{6}:$ Price perception of PDP $\rightarrow$ Stickiness to an online store & $0.44 * * *$ & 7.90 & Supported \\
Stickiness to online store $\rightarrow$ WTP & $0.31^{* * *}$ & 5.32 & \\
\hline
\end{tabular}

Note: ${ }^{*} \mathrm{p}<0.05 ;{ }^{* *} \mathrm{p}<0.01 ;{ }^{* * *} \mathrm{p}<0.001$ 
Table 5 mentions the mediation result. The t-value of the mediation is significant, with a value of 8.09. The indirect effect with a value of 0.13 lies well within the lower and upper cut-off confidence interval of 0.09 to 0.18 . Thus, showing full mediation.

Table 5. Mediation results

\begin{tabular}{lcccccc}
\hline \multicolumn{1}{c}{ Path tested } & $\begin{array}{c}\text { Direct } \\
\text { mediator }\end{array}$ & $\begin{array}{c}\text { Indirect } \\
\text { effect }\end{array}$ & & $\begin{array}{c}\text { Indirect effect } \\
\text { confidence level }\end{array}$ & $\begin{array}{c}\mathrm{p} \text { - } \\
\text { value }\end{array}$ & Conclusion \\
\hline $\begin{array}{l}\text { Price perception of PDP } \\
\rightarrow \text { Stickiness to online store } \\
\rightarrow \text { WTP }\end{array}$ & $0.29(8.09)$ & 0.13 & 0.09 & 0.18 & 0.001 & Mediation \\
\hline
\end{tabular}

Note: Values presented are regression coefficients - $\mathrm{t}$-values in parentheses

\section{Discussion}

Results showed that the recommendation system appears to have a more significant direct influence on price fairness of PDP and an indirect impact on willingness to pay. Collectively, price consciousness, product knowledge, involvement, recommendation system combines to influence price fairness perception to influence further willingness to pay mediated through SoS. Much of the knowledge gained from existing offline retailing research applies to the online retailing context (Jiang \& Rosenbloom, 2005). Overall, the results showed support for all hypotheses. It can be observed from data analysis that our model had a good fit.

There are some interesting findings of this study to be pointed out consistent with previous studies. Price is an essential factor in consumer decision-making and the purchase process. Therefore, it largely influences fairness perception and consumer behavioral outcomes. The results showed price consciousness directly affects the perception of price fairness of PDP and indirectly influences willingness to pay. Our results are consistent with past studies that provide empirical evidence that PDP impacts the fairness perception of consumers. As expected, product knowledge had a significant association with price fairness of PDP, which in turn is related to customer willingness to pay (Chen et al., 2019). Similarly, involvement has a significant association with price fairness of PDP, which in turn is related to customer willingness to pay (Malar et al., 2011).

\section{Implications}

\subsection{Theoretical Implications}

The study adds the role of the recommender system to the extant research. To enable retailers to provide personalized prices, the role of the recommender system is vital. $35 \%$ of revenue generated from Amazon.com was through recommendations 
based on sophisticated algorithms and predictive models (Mackenzie et al., 2013). Consumers' reliability on the recommendation system, precision, and prediction accuracy plays a vital role in influencing purchase decisions. The study links the function of the recommender system in directly influencing the price fairness of PDP and an indirect influence on willingness to pay. The key finding of the research is that the recommender system is vital among other antecedents for the price fairness of PDP evident from a higher t-value (8.96).

Consumer loyalty in the e-marketplace is complex. Hence stickiness to online stores has to be considered. Drawing parallels from the study of Beatty and Smith (1987), an involved consumer will spend a lot of time and effort to find their product and price offered through the online store by visiting the online store site frequently. Not many studies have studied the mediating role of SoS on price fairness and willingness to pay (Roy et al., 2014). This finding is a welcome addition to literature seeking to understand the role of stickiness in customers' willingness to pay. It is important because customer stickiness to online stores signifies a psychological attachment to visiting those sites (Roy et al., 2014). Also, the results show the full mediation effect of SoS on price fairness and willingness to pay.

Finally, our study provides a significant contribution to pricing literature. Most of the existing studies had focused on studying how price and pricing strategies affect consumer purchase decisions in a traditional economy setting. At the same time, this paper focused on examining consumer characteristics influencing price personalization and how it impacts customer fairness perception.

\subsection{Managerial Implications}

This paper explores customer willingness to pay as the vital outcome in a PDP context. It also investigates the mediating role of stickiness to the online store on customer willingness to pay. We have included antecedent that affects the price fairness of PDP. In addition, this study offers important insights for companies to understand online consumer behavior. Understanding how consumers perceive personalized dynamic pricing in an electronic marketplace is vital. It impacts decision-making at a micro-level in marketing management and a macro-level in policy decision-making by organizations and regulators. First, the results found that online shoppers will feel special and acknowledged to receive a personalized price, resulting in a willingness to pay.

Given the phenomenal growth of online retailing accelerated by external factors such as pandemics and competition among leading players (Sheth \& Unnikrishnan, 2020), enticing consumers is one of the critical requirements for an online retailer to sustain intense competition and prevent switching behavior among consumers. Also, about $74 \%$ of online buyers do not have a brand fixed before they start searching for their product and most of the consumers search for around 2 to 3 weeks on an online platform (Jain et al., 2019). Firms can use this search duration window to attract consumers by providing personalized offers through recommendation systems. Data 
captured through stickiness to an online store can aid firms in arriving at customized offers. Second, information on the product sought should be readily available on the site so that consumers can browse through and decide without any search frictions. Visual aids detailed product information to help consumers understand the products is essential. These aids can improve consumer knowledge and involvement towards the product (Ford et al., 2018). This aspect can also be addressed by having clear and visual assistance to product description.

Over time, customer characteristics and determination of customer value potential keep evolving. A reliable method to periodically evaluate customer value measures is necessary for managers to track changing customer characteristics. In ecommerce, platform stickiness can be used to assess customer value by looking at the frequency and duration of visits and the number of purchases the consumer has made. Thus, it is evident that the antecedents chosen for study in this paper provide insights into customer value co-creation and price fairness of PDP.

\section{Limitations and Future Research}

While this research has some significant contributions, it has its limitations too. For instance, it did not consider the role of risk attitude on personalized pricing, which may have affected the perception of fairness. Future research can study the part of risk attitude among consumers to understand various pricing cues and explore its impact on consumers' real buying behavior. Studies can do further experimental investigation on the influence of norms and price transparency on customer perception of fairness (Güngör \& Bilgin, 2011; Kaynak \& Eksi, 2011; Arcuri, 2020). Analyzing how firms can arrive at the segmentation base of PDP, its impact on personalization-privacy and trust can also be explored. Lastly, future studies could be extended to identify potential consequences of unfair perception of personalized price, looking into the intervening effects of personalized social media advertisements and personalized prices. The dynamic nature of PDP and impulse purchase behavior can be explored further (Naikoo et al., 2021).

\section{References}

Acquisti, A., Taylor, C., \& Wagman, L. (2016). The Economics of Privacy. Journal of Economic Literature, 54(2), 442-492. https://doi.org/10.1257/jel.54.2.442

Adams, J. S. (1965). Inequity in Social Exchange. Advances in Experimental Social Psychology, 267-299. https://doi.org/10.1016/s0065-2601(08)60108-2

Anderson, J. C., \& Gerbing, D. W. (1988). Structural equation modeling in practice: A review and recommended two-step approach. Psychological Bulletin, 103(3), 411-423. https://doi.org/10.1037/0033-2909.103.3.411

Arcuri, M. C. (2020). General Data Protection Regulation (GDPR) implementation: What was the impact on the market value of European financial institutions? Eurasian Journal of Business and Economics, 13(25), 1-20. https://doi.org/10.17015/ejbe.2020.025.01 
Impact of Consumer Behavior Pertaining to Personalization of Price in an E-Commerce Context

Basaran, U., \& Buyukyilmaz, O. (2015). The effects of utilitarian and hedonic values on young consumers' satisfaction and behavioral intentions. Eurasian Journal of Business and Economics, 8(16), 1-18. https://doi.org/10.17015/ejbe.2015.016.01

Beatty, S. E., \& Smith, S. M. (1987). External search effort: An investigation across several product categories. Journal of Consumer Research, 14(1), 83. https://doi.org/10.1086/209095

Bollen, K. A., \& Stine, R. A. (1992). Bootstrapping goodness-of-fit measures in structural equation models. Sociological Methods \& Research, 21(2), 205-229. https://doi.org/10.1177/0049124192021002004

Broeder, P., \& Wildeman, N. (2020). The color red for emotion in cross-cultural e-commerce. Eurasian Journal of Business and Economics, 13(25), 75-89. https://doi.org/10.17015/ejbe.2020.025.05

Brucks, M. (1985). The effects of product class knowledge on information search behavior. Journal of Consumer Research, 12(1), 1. https://doi.org/10.1086/209031

Burke, R., Felfernig, A., \& Göker, M. H. (2011). Recommender Systems: An overview. Al Magazine, 32(3), 13-18. https://doi.org/10.1609/aimag.v32i3.2361

Chen, J., Wang, H., \& Gao, W. (2019). How do goal and product knowledge specificity influence online channel choice? A polynomial regression analysis. Electronic Commerce Research and Applications, 35, 100846. https://doi.org/10.1016/j.elerap.2019.100846

Dinerstein, M., Einav, L., Levin, J., \& Sundaresan, N. (2018). Consumer price search and platform design in internet Commerce. American Economic Review, 108(7), 1820-1859. https://doi.org/10.1257/aer.20171218

Dubé, J.-P., \& Misra, S. (2017). Personalized pricing and consumer welfare. NBER Working Paper Series, Working Paper: 23775. https://doi.org/10.3386/w23775

Ford, D. L., Ziegler, L. L., Fang, R., \& Holmes IV, O. (2018). Exploring knowledge sharing in a professional network: A Central Eurasian case. Eurasian Journal of Business and Economics, 10(20), 1-22. https://doi.org/10.17015/ejbe.2018.021.01

Fornell, C., \& Larcker, D. F. (1981). Evaluating structural equation models with unobservable variables and measurement error. Journal of Marketing Research, 18(1), 39-50. https://doi.org/10.1177/002224378101800104

Garbarino, E., \& Maxwell, S. (2010). Consumer response to norm-breaking pricing events in ecommerce. Journal of Business Research, 63(9-10), 1066-1072. https://doi.org/10.1016/j.jbusres.2008.12.010

Gaskin, J. (2016) "My Indirect Effects" User-Defined Estimand for AMOS from Gaskination's StatWiki.

Gefen, D., Karahanna, E., \& Straub, D. W. (2003). Trust and TAM in online shopping: An integrated model. MIS Quarterly, 27(1), 51-90.

Güngör, Ö. M., \& Bilgin, Z. F. (2011). Customer's Advisory, Organizational Openness, and Capability: The Locus of Value Creation. Eurasian Journal of Business and Economics, 4(7), 8197.

Hazée, S., Delcourt, C., \& Van Vaerenbergh, Y. (2017). Burdens of access: understanding customer barriers and barrier-attenuating practices in access-based services. Journal of Service Research, 20(4), 441-456. https://doi.org/10.1177/1094670517712877 
Hu, L., \& Bentler, P. M. (1999). Cut-off criteria for fit indexes in covariance structure analysis: Conventional criteria versus new alternatives. Structural Equation Modeling: A Multidisciplinary Journal, 6(1), 1-55. https://doi.org/10.1080/10705519909540118

Jain, N., Sanghi, K., and Pateriya, A. (2019). "Digital Powers Consumer Durables: A \$23Bn opportunity by2023". Available at: https://www.bcg.com/en-in/digital-powers-consumerdurables-a-23-bn-opportunity-by-2023

Jiang, P., \& Rosenbloom, B. (2005). Customer intention to return online: Price Perception, attribute-level performance, and satisfaction unfolding over time. European Journal of Marketing, 39(1/2), 150-174. https://doi.org/10.1108/03090560510572061

Kaynak, R., \& Eksi, S. (2011). Ethnocentrism, Religiosity, Environmental and Health Consciousness: Motivators for Anti-Consumers. Eurasian Journal of Business and Economics, $4(8), 31-50$.

Koufaris, M., Kambil, A., \& Labarbera, P. A. (2001). Consumer behavior in web-based Commerce: An empirical study. International Journal of Electronic Commerce, 6(2), 115-138. https://doi.org/10.1080/10864415.2001.11044233

Krämer, A., \& Kalka, R. (2017). How digital disruption changes pricing strategies and price models. In A. Khare, B. Stewart, \& R. Schatz (eds.), Phantom Ex Machina (pp. 87-103). Springer https://doi.org/10.1007/978-3-319-44468-0 6

Lastner, M. M., Fennell, P., Folse, J. A., Rice, D. H., \& Porter, M. D. (2019). I guess that is fair: How the efforts of other customers influence buyer price fairness perceptions. Psychology \& Marketing, 36(7), 700-715. https://doi.org/10.1002/mar.21206

Lee, J.-M., \& Rha, J.-Y. (2016). Personalization-privacy paradox and consumer conflict with the use of location-based Mobile Commerce. Computers in Human Behavior, 63, 453-462. https://doi.org/10.1016/i.chb.2016.05.056

Lemon, K. N., \& Verhoef, P. C. (2016). Understanding customer experience throughout the customer journey. Journal of Marketing, 80(6), 69-96. https://doi.org/10.1509/im.15.0420

Lichtenstein, D. R., Bloch, P. H., \& Black, W. C. (1988). Correlates of price acceptability. Journal of Consumer Research, 15(2), 243. https://doi.org/10.1086/209161

Lin, J. C.-C. (2007). Online stickiness: Its antecedents and effect on purchasing intention. Behaviour \& Information Technology, 26(6), 507-516. https://doi.org/10.1080/01449290600740843

MacKenzie, I., Meyers, C., and Noble, S., (2013). How retailers can keep up with consumers. Available at: https://www.mckinsey.com/industries/retail/our-insights/how-retailers-cankeep-up-with-consumers

Malär, L., Krohmer, H., Hoyer, W. D., \& Nyffenegger, B. (2011). Emotional brand attachment and brand personality: The relative importance of the actual and the ideal self. Journal of Marketing, 75(4), 35-52. https://doi.org/10.1509\%2Fjmkg.75.4.35

Naikoo, M. W., Peer, A. H., Ahmed, F., \& Ishtiaq, M. (2021). Monetary policy and Housing Prices Dynamics in India. Eurasian Journal of Business and Economics, 14(27), 47-61. https://doi.org/10.17015/ejbe.2021.027.03

Podsakoff, P. M., MacKenzie, S. B., \& Podsakoff, N. P. (2012). Sources of method bias in social science research and recommendations on how to control it. Annual Review of Psychology, 63(1), 539-569. https://doi.org/10.1146/annurev-psych-120710-100452 
Impact of Consumer Behavior Pertaining to Personalization of Price in an E-Commerce Context

Priester, A., Robbert, T., \& Roth, S. (2020). A special price just for you: Effects of personalized dynamic pricing on Consumer Fairness Perceptions. Journal of Revenue and Pricing Management, 19(2), 99-112. https://doi.org/10.1057/s41272-019-00224-3

Rao, A. R., \& Sieben, W. A. (1992). The effect of prior knowledge on price acceptability and the type of information examined. Journal of Consumer Research, 19(2), 256. https://doi.org/10.1086/209300

Richards, T. J., Liaukonyte, J., \& Streletskaya, N. A. (2016). Personalized pricing and Price Fairness. International Journal of Industrial Organization, 44, 138-153. https://doi.org/10.1016/j.ijindorg.2015.11.004

Roy, S. K., M. Lassar, W., \& T. Butaney, G. (2014). The mediating impact of stickiness and loyalty on word-of-mouth promotion of retail websites. European Journal of Marketing, 48(9/10), 1828-1849. https://doi.org/10.1108/ejm-04-2013-0193

Sheikh, S. M., \& Basti, M. (2015). Customer satisfaction in business to consumer (B2C) ecommerce: A comparative study of Turkey and Pakistan. Eurasian Journal of Business and Economics, 8(16), 73-100. https://doi.org/10.17015/ejbe.2015.016.05

Sheth, A. \& Unnikrishnan, S. (2020, June 16). How India shops online. Bain \& Company, Inc. https://www.bain.com/insights/how-india-shops-online/

Wang, Y-S., Tang, T-I. and Tang, J-E.E. (2001). An instrument for measuring customer satisfaction toward web sites that market digital products and services, Journal of Electronic Commerce Research, 2(3), 89-102.

Xia, L., Monroe, K. B., \& Cox, J. L. (2004). The price is unfair! A conceptual framework of Price Fairness Perceptions. Journal of Marketing, 68(4), 1-15. https://doi.org/10.1509/jmkg.68.4.1.42733

Zaichkowsky, J. L. (1985). Measuring the involvement construct. Journal of Consumer Research, 12(3), 341. https://doi.org/10.1086/208520

Zielke, S., \& Komor, M. (2014). Cross-national differences in price-role orientation and their impact on retail markets. Journal of the Academy of Marketing Science, 43(2), 159-180. https://doi.org/10.1007/s11747-014-0379-4 